\title{
Cuidados Paliativos como Prática Humanizadora em um Hospital Público
}

\author{
Silva, Ana Paula da; Lino, Ivanise Regina de Paiva; Novelo, Elizabeth C. Martinez; Bessa, \\ Tânia Regina Melhado; Rocha, Juraci Aparecida; Oliveira, Maridite C. Gomes de \\ Hospital Geral de Sao Mateus — hsm-apsilva@saude.sp.gov.br
}

Introdução Os hospitais públicos de porta aberta vêm recebendo um número cada vez maior de pacientes com indicação de cuidados paliativos. o uso deste serviço é muito restrito e não consegue absorver a demanda. Está é uma realidade cruel e desumana para com estas pessoas que necessitam deste tipo de assistência. Objetivo Estabelecer no hospital geral, assistência em cuidados paliativos, com foco na comunicação e humanização no cuidar. Desenvolver um conjunto de ações interdisciplinares visando minimizar o sofrimento do paciente e de seus familiares, proporcionando-Ihe conforto e aceitação da doença, oferecendo-lhe recursos necessários para que consiga desfrutar do tempo de sua vida de maneira digna e menos dolorosa. Metodologia Este trabalho foi realizado em três etapas. Primeira Etapa: - Criação do grupo de trabalho multidisciplinar com formação e experiência na área para desenvolvimento do plano de ação. Segunda Etapa: a)Sistematização de conceitos e estudos dos referenciais teóricos b) Realização de pesquisa para identificar o conhecimento dos profissionais e a possibilidade de implantação de cuidados paliativos na instituição. c) Definição dos critérios de inclusão em cuidados paliativos e identificação da equipe de referencia d) Elaboração do protocolo de atendimento com fluxograma e) Cronograma de discussão do protocolo com equipe multiprofissional Terceira Etapa: - Disseminação para a instituição deste novo olhar para a assistência, com a realização de palestras e material de divulgação como banners, faixas e folders. Resultados Foram realizados reuniões com equipe multidisciplinar totalizando 7 encontros (diretores, supervisores, médicos, enfermeiros, assistentes sociais, psicólogos, fisioterapeutas, fonoaudiólogos e farmacêuticos). - Encontros com capelania, corpo de voluntariado e comunidade. - 09 oficinas de sensibilização para todos os profissionais do hospital totalizando até o momento 420 participantes. - Encontro anual de humanização com o tema de cuidados paliativos com a realização de 07 palestras de profissionais membros de diversos Serviços Especializados em Cuidados Paliativos do Município de São Paulo. - Confecção do guia de orientação para uso de medicamentos em cuidados paliativos. (Serviço de farmácia, Diretoria médica e de Enfermagem). Conclusão Esta iniciativa tem provocado mudanças no olhar e na postura dos profissionais que desenvolveram uma percepção e uma escuta mais refinada para as necessidades desses pacientes, solicitando a opinião da equipe de cuidados paliativos para sugerir procedimentos diferenciados nesta área. a pratica de cuidados paliativos tem mostrado a importância e as possibilidades de um atendimento humanizado que preste cuidados de forma a atender o paciente e seus familiares integralmente, proporcionando dignidade e maior qualidade de vida

Silva, Ana Paula da; Lino, Ivanise Regina de Paiva; Novelo, Elizabeth C. Martinez; Bessa, Tânia Regina Melhado; Rocha, Juraci Aparecida; Oliveira, Maridite C. Gomes de. Cuidados Paliativos como Prática Humanizadora em um Hospital Público. In: Anais do Congresso Internacional de Humanidades \& Humanização em Saúde [= Blucher Medical Proceedings, num.2, vol.1]. São Paulo: Editora Blucher, 2014. ISSN 2357-7282

DOI 10.5151/medpro-cihhs-10683 